\title{
Lightweight Design and Optimization Effect Evaluation of Hydro Generator Set
}

\author{
Yongyi Liao ${ }^{1,2}$, Baiyu Liao ${ }^{1}$ \\ ${ }^{1}$ Key Laboratory of Vibration and Noise under Ministry of Education of Yunnan Province, Kunming University \\ of Science and Technology, Kunming 650500, China. \\ ${ }^{2}$ Continuing Education College, Kunming University of Science and Technology, Kunming 650051, China. Email: \\ yongyiliao@163.com
}

With the increase of hydro generators capacity and unit size, the requirement of lightweight is prominent. Taking a mixed-flow hydro generator as the research objects, the strength, the stiffness and the dynamic characteristics of upper bracket, stator frame, lower bracket and head cover have been simulated and analyzed by means of establishing their finite element models. Based on sizing optimization design method, plate thicknesses of the main parts were selected as the design variables, and strength and stiffness were taken as the constraint conditions to optimize them with the minimum mass as the objective function. Through lightweight optimization design, the maximum normal stress and maximum displacement of the optimized main parts are within the allowable value range, modal analysis shows that their dynamic characteristics meet the requirements. The lightweight optimization design reduced the weight of hydro generator by $3457 \mathrm{~kg}$ in total. Optimization effect evaluation under full load operation and site test between the original and improved hydro generator set show that the dynamic characteristics are improved and the performances meet the design requirements.

Keywords: Hydro generator set, Lightweight optimization design, Sizing optimization, Structural improvement

\section{Introduction}

Hydropower is the preferred power generation mode in most countries. Compared with thermal power, nuclear power, solar power and wind power, hydropower has the advantages of green, renewable and low cost. With the increase of water turbine capacity and unit size, water turbines are developing towards high water head, large capacity and structure lightweight [1]. There has been some progress in structural optimization design and dynamic characteristics analysis of water turbine and its components in recent years. The structural optimization design is mainly proceed with the shape, strength and stiffness of the corresponding parts [2-4]. Li Wei et al. [5] calculated the temperature field and stress field of hydrogenerator stator by using finite element method, and analyzed the reason for outer-movement of stator core laminated sheets under the action of electromagnetic tension. Based on traditional machine design method and the mechanical reliability design method, Qi Xueyi et al. [6] designed and calculated water turbine head cover, the comparison and analysis of the two methods are described. Zhao Daoli et al. [7] applied finite element method to analyze the strength of the water turbine runner and proposed two design schemes to improve the stress of runner blade. Shao Guohui et al. [8] improved the design for flow passage components (spiral case, draft tube, runner etc.) of water turbine through CFD analysis, the analysis and test data meet the requirements of hydraulic design parameters. For the dynamic characteristics, the natural frequencies and vibration modes of structures are mainly analyzed, by increasing the lower-order natural frequencies, structural resonance is suppressed to avoid excitation frequencies [4, 9]. Yuan Xiaoming et al. [10] established the coupling model of stator, rotor and upper bracket of hydro generator, analyzed natural frequency and harmonic response of the model, and obtained the influences of the stiffness of rib and jack on the vibration amplitude. The above studies are mainly concerned with structural optimization design and dynamic performance analysis of water turbine parts, and there are relatively few researches on lightweight optimization designs.

Taking a mixed-flow hydro generator in an electrical machinery plant as the research objects, its assembly diagram is shown in Fig. 1. The upper bracket, stator frame, lower bracket and head cover are the main pars of hydro generator, in addition to meeting operational performance in structure design, the structural lightweight optimization should also be realized under the requirement of ensuring strength, stiffness and dynamic characteristics. According to the actual size and working conditions of upper bracket, stator frame, lower bracket and head cover, their finite element models are established respectively, and the dynamic characteristics are simulated and analysed [11-14]. Based on structure sizing optimization design method [1517], plate thicknesses of upper bracket, stator frame, 
lower bracket and head cover are selected as the design variables, and the two design indexes of strength and stiffness are taken as the constraint conditions to optimize them with the minimum mass as the objective function.

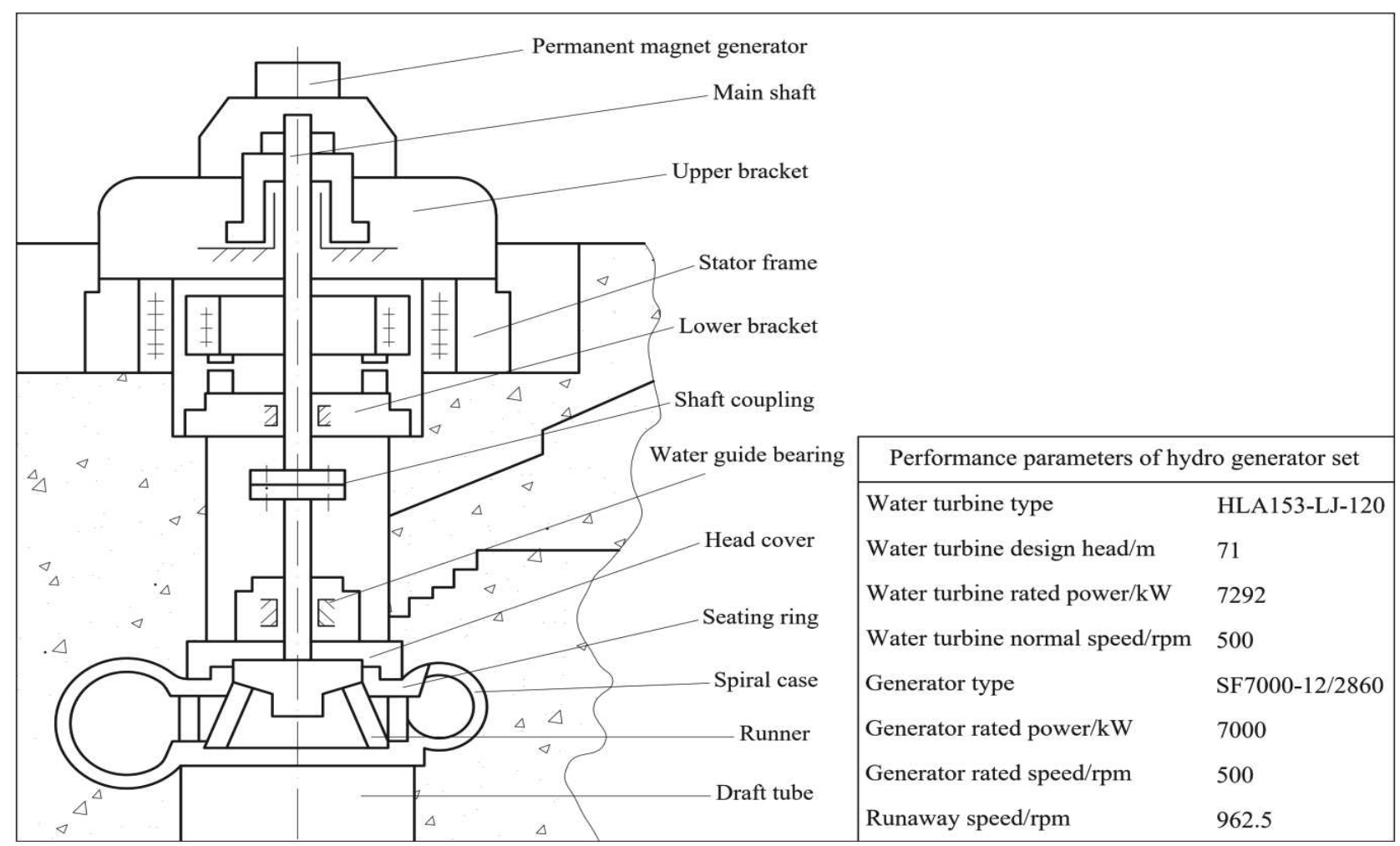

Fig. 1 Assembly diagram of bydro generator set

\section{Lightweight optimization design of upper bracket}
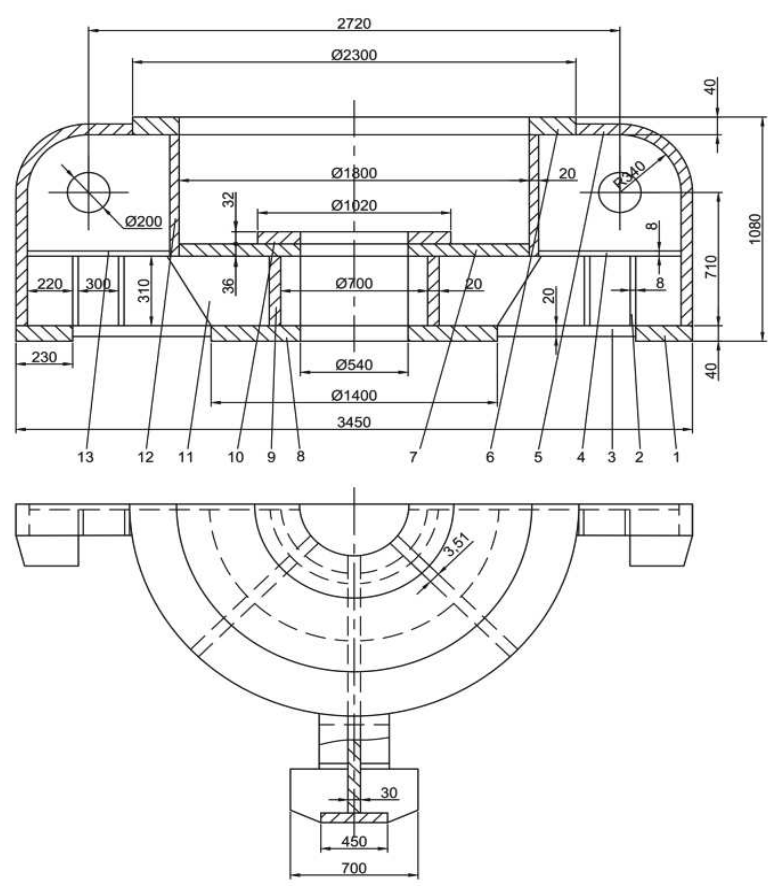

1-Baseplate 2-Vertical rib 3-Lower radial plate 4-Middle radial plate 5-Upper radial plate 6-Upper ring 7Middle ring 8-Lower ring 9-Lower housing 10-Facing plate 11,13-rib plate 12-Upper housing

Fig. 2 Structure diagram of upper bracket
The upper bracket is made of carbon structural steel with different thickness. The structure diagram is shown in Fig. 2, which is mainly composed of upper ring, middle ring, lower ring, housing, radial plate, rib plate and baseplate.

The upper bracket is a complex structure of plate box body. As three-dimensional triangular shell element can be accurately classified complex three-dimensional structures, it is composed of plane stress membrane element and plate bending element, thus bending and shear force can be transferred, its mechanical characteristics are closer to force status of the upper bracket. Therefore, three-dimensional triangular shell element is used as element of finite element model for the upperer bracket structure. The entire finite element model consists of 870 elements, 440 nodes, and 2640 degrees of freedom.

In calculation the load of the upper bracket, the load acting on the wear-resisting plate by the thrust end of the rotor under normal working conditions is considered [12].

Based on sizing optimization design principle [1517], in the lightweight optimization design of upper bracket, considering that the overall structure size, such as the installation and mating dimensions cannot be changed, 8 kinds of plate thicknesses $\boldsymbol{X}=\left[x_{1}, x_{2}, \cdots, x_{8}\right]^{\mathrm{T}}$ of upper bracket are selected as design variables, as shown in Tab. 1 . The mass of upper 
bracket $W(\boldsymbol{X})$ is taken as the objective function of optimization design.

With conforming to stress and deformation of upper bracket as the constraint conditions, namely, the maximum stress and the maximum displacement of nodes in each element group of the structure are less than allowable values, that is

$$
\begin{cases}\sigma_{i} \leq\left[\sigma_{i}\right] & i=1,2, \cdots, p \\ \delta_{j} \leq\left[\delta_{j}\right] & j=1,2, \cdots, h\end{cases}
$$

In above equation, $\left[\sigma_{i}\right]$ is allowable stress of element group $i,\left[\delta_{j}\right]$ is allowable displacement of node $j$. Then, the mathematical model of lightweight optimization design is obtained as

$$
\left\{\begin{array}{c}
\min W(\boldsymbol{X}) \\
\text { s.t. }\left\{\begin{array}{c}
\sigma_{i} \leq\left[\sigma_{i}\right] \quad i=1,2, \cdots, p \\
\delta_{j} \leq\left[\delta_{j}\right] \quad j=1,2, \cdots, h
\end{array}\right. \\
\boldsymbol{X}=\left[x_{1}, x_{2}, \cdots, x_{8}\right]^{\mathrm{T}}
\end{array}\right.
$$

According to the mathematical model, with the objective of lightweight design and conforming to stress and deformation as the constraint conditions, the upper bracket structure is analyzed and calculated by using the compound form method with optimization iteration. The compound form method is developed from simplex method, which overcomes the dimensionality reduction of easy to occur in simplex method, its shape does not need to keep regular form, and there is no special requirement on the properties of objective function and constraint conditions. Every time the shape of the compound shape is changed, it is closer to optimum. After repeated iteration until the best approximation, the lightweight optimization results are obtained, as shown in Tab. 1.

The maximum stress, maximum displacement and natural frequencies for original and improved finite element model under loads are analyzed and calculated respectively. The comparative results are shown in Tab. 2.

Tab. 1 Optimization design results of upper bracket

\begin{tabular}{cccc}
\hline Design variable & Parts name & Original value $/ \mathrm{mm}$ & $\begin{array}{c}\text { Optimal standardized } \\
\text { value } / \mathrm{mm}\end{array}$ \\
\hline$x_{1}$ & Upper ring & 40 & 30 \\
$x_{2}$ & Upper housing & 20 & 12 \\
$x_{3}$ & rib plate & 30 & 20 \\
$x_{4}$ & Upper radial plate & 25 & 16 \\
$x_{5}$ & Baseplate & 40 & 30 \\
$x_{6}$ & Lower radial plate & 20 & 16 \\
$x_{7}$ & Lower ring & 40 & 20 \\
$x_{8}$ & Lower housing & 20 & 16 \\
\hline
\end{tabular}

Tab. 2 Comparison of dynamic characteristics of upper bracket

\begin{tabular}{ccc}
\hline Performance parameter & Original model & Optimized model \\
\hline Maximum displacement $/ \mathrm{mm}$ & 0.22 & 0.33 \\
Node number & 193 & 224 \\
Maximum stress $/ \mathrm{MPa}$ & 21.95 & 28.03 \\
Element group number & 12 & 12 \\
\hline First natural frequency $/ \mathrm{Hz}$ & 149.54 & 116.99 \\
Second natural frequency $/ \mathrm{Hz}$ & 171.26 & 120.60 \\
Third natural frequency $/ \mathrm{Hz}$ & 176.85 & 121.03 \\
\hline Structure mass $/ \mathrm{kg}$ & 2067 & 1540 \\
Reduce weight $/ \mathrm{kg}$ & & 527 \\
Weight reduction ratio & & $25.5 \%$ \\
\hline
\end{tabular}

\section{Lightweight optimization design of stator frame}

The stator frame is made of carbon structural steel Q235B with different thickness. Its structure diagram is shown in Fig. 3, which is mainly composed of upper ring, verical rib, middle ring, supporting ring, lower ring and housing. Stator frame is a complex structure of plate box body. Three-dimensional triangular shell element is used as element of finite element model for stator frame structure. The entire finite element model consists of 28 element groups, 1740 elements, 732 nodes, and 4328 degrees of freedom.

In load calculation, the loads on the stator frame under rated operating condition and half the magnetic poles short circuit condition are analyzed, and the largest loads under the most unfavorable working condition are considered [13]. 


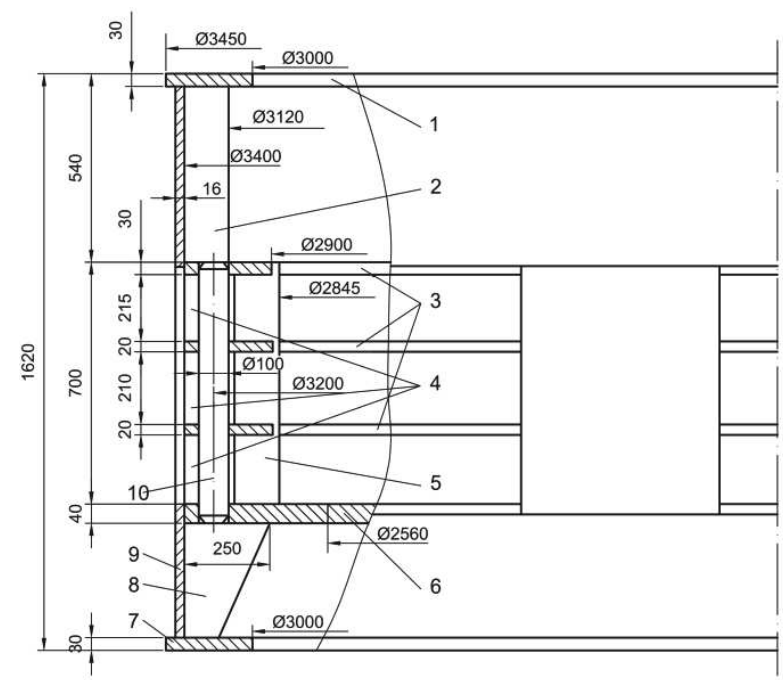

1-Upper ring 2 -Vertical rib $\times 12$ equispaced 3 -Middle ring 4 -Vertical rib $\times 12$ equispaced 5 -Vertical rib $\times 36$ equispaced 6-Supporting ring 7-Lower ring 8-Vertical rib $\times 12$ equispaced 9 -Housing 10 -Vertical column $\times 4$ equispaced

Fig. 3 Structure diagram of stator frame
6 kinds of plate thicknesses $\boldsymbol{X}=\left[x_{1}, x_{2}, \cdots, x_{6}\right]^{\mathrm{T}}$ of stator frame are selected as design variables. The mass $W(\boldsymbol{X})$ of stator frame is taken as the objective function of optimization design. With conforming to stress and deformation as the constraint conditions, the mathematical model of lightweight optimization design is obtained as

$$
\left\{\begin{array}{c}
\min W(\boldsymbol{X}) \\
\text { s.t. }\left\{\begin{array}{cc}
\sigma_{i} \leq\left[\sigma_{i}\right] & i=1,2, \cdots, p \\
\delta_{j} \leq\left[\delta_{j}\right] \quad j=1,2, \cdots, h
\end{array}\right. \\
\boldsymbol{X}=\left[x_{1}, x_{2}, \cdots, x_{6}\right]^{\mathrm{T}}
\end{array}\right.
$$

The lightweight optimization results are obtained by repeated iteration until the best approximation, shown in Tab. 3.

The maximum stress, maximum displacement and natural frequencies for original and improved finite element model under loads are analyzed and calculated respectively. The results are shown in Tab. 4.

Tab. 3 Optimization design results of stator frame

\begin{tabular}{cccc}
\hline Design variable & Parts name & Original value $/ \mathrm{mm}$ & $\begin{array}{c}\text { Optimal standardized } \\
\text { value } / \mathrm{mm}\end{array}$ \\
\hline$x_{1}$ & Vertical & 30 & 20 \\
$x_{2}$ & rib 2 & 30 & 25 \\
$x_{3}$ & Middle ring & 30 & 20 \\
$x_{4}$ & Vertical & & 20 \\
$x_{5}$ & rib 4 & 30 & 36 \\
$x_{6}$ & Vertical & 40 & 12 \\
\hline
\end{tabular}

Tab. 4 Comparison of dynamic characteristics of stator frame

\begin{tabular}{|c|c|c|}
\hline Performance parameter & Original model & Optimized model \\
\hline Maximum displacement/mm & 0.225 & 0.456 \\
\hline Node number & 8 & 8 \\
\hline Maximum stress/MPa & 54.0 & 54.5 \\
\hline Element group number & 1 & 6 \\
\hline First natural frequency $/ \mathrm{Hz}$ & 105.72 & 104.80 \\
\hline Second natural frequency $/ \mathrm{Hz}$ & 124.06 & 121.91 \\
\hline Third natural frequency/Hz & 155.79 & 149.89 \\
\hline Fourth natural frequency $/ \mathrm{Hz}$ & 233.24 & 233.03 \\
\hline Structure mass / kg & 7800 & 5910 \\
\hline Reduce weight / kg & & 1890 \\
\hline Weight reduction ratio & & $24.2 \%$ \\
\hline
\end{tabular}

\section{Lightweight optimization design of lower bracket}

The Lower bracket is a complex structure of plate box body, which is mainly composed of upper ring, lower ring, housing and rib plate. Lower bracket is equipped with hydraulic cylinder, lower guide bearing, etc., which is fixed on the concrete foundation by bolts of support arm. Lower bracket is made of carbon structural steel Q235B with different thickness. The structure diagram is shown in Fig. 4. 


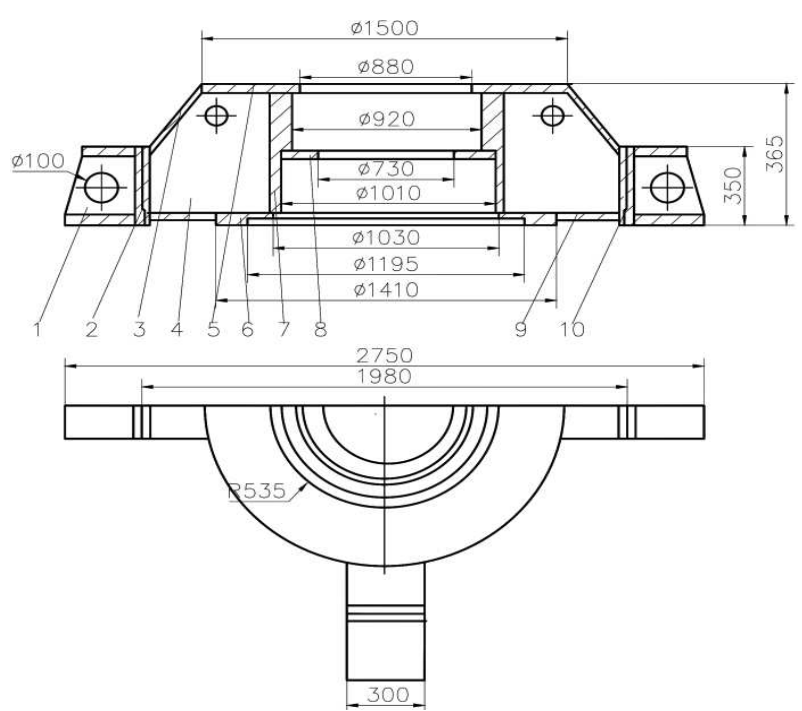

1-Support arm 2, 3, 9-Bearing plate 4-Rib plate 5-Upper ring 6-Lower ring 7-Housing 8-Retainer ring 10Bolt

Fig. 4 Structure diagram of lower bracket
In a similar manner, the entire finite element model of lower bracket consists of 18 element groups, 1036 elements, 548 nodes, and 3288 degrees of freedom. The loads acting on the lower bracket are analyzed and calculated to simulate the working condition [14]. 14 kinds of plate thicknesses $\boldsymbol{X}=\left[x_{1}, x_{2}, \cdots \cdots x_{14}\right]^{\mathrm{T}}$ are selected as design variables, and the mass of lower bracket $W(\boldsymbol{X})$ is taken as the objective function of optimization design. The mathematical model of lower bracket lightweight optimization design is obtained as

$$
\left\{\begin{array}{c}
\min W(\boldsymbol{X}) \\
\text { s.t. }\left\{\begin{array}{c}
\sigma_{i} \leq\left[\sigma_{i}\right] \quad i=1,2, \cdots, p \\
\delta_{j} \leq\left[\delta_{j}\right] \quad j=1,2, \cdots, h
\end{array}\right. \\
\boldsymbol{X}=\left[x_{1}, x_{2}, \cdots, x_{14}\right]^{\mathrm{T}}
\end{array}\right.
$$

The optimized design parameters of lower bracket are determined by using the compound form method with optimization iteration, the lightweight optimization results are shown in Tab. 5 .

Tab. 5 Optimization design results of lower bracket

\begin{tabular}{cccc}
\hline Design variable & Original value $/ \mathrm{mm}$ & Optimal value $/ \mathrm{mm}$ & Standardized value $/ \mathrm{mm}$ \\
\hline$x_{1}$ & 20 & 12.395 & 15 \\
$x_{2}$ & 60 & 48.59 & 50 \\
$x_{3}$ & 15 & 3.198 & 6 \\
$x_{4}$ & 15 & 7.198 & 10 \\
$x_{5}$ & 20 & 12.395 & 15 \\
$x_{6}$ & 20 & 6.796 & 10 \\
$x_{7}$ & 25 & 12.379 & 15 \\
$x_{8}$ & 20 & 6.796 & 10 \\
$x_{9}$ & 15 & 6.796 & 10 \\
$x_{10}$ & 20 & 10.796 & 12 \\
$x_{11}$ & 50 & 33.59 & 36 \\
$x_{12}$ & 20 & 6.796 & 10 \\
$x_{13}$ & 20 & 6.796 & 10 \\
$x_{14}$ & 25 & 13.395 & 15 \\
\hline
\end{tabular}

The maximum stress, maximum displacement and natural frequencies for original and improved finite element model under loads are analyzed and calculated respectively. The results are shown in Tab. 6.

Tab. 6 Comparison of dynamic characteristics of lower bracket

\begin{tabular}{|c|c|c|}
\hline Performance parameter & Original model & Optimized model \\
\hline Maximum displacement/mm & 0.0823 & 0.243 \\
\hline Node number & 72 & 66 \\
\hline Maximum stress/MPa & 32.5 & 94.6 \\
\hline Element group number & 13 & 2 \\
\hline First natural frequency $/ \mathrm{Hz}$ & 306.41 & 185.09 \\
\hline Second natural frequency $/ \mathrm{Hz}$ & 345.42 & 188.43 \\
\hline Third natural frequency/Hz & 350.24 & 188.48 \\
\hline Fourth natural frequency $/ \mathrm{Hz}$ & 350.34 & 191.41 \\
\hline Structure mass / kg & 1780 & 990 \\
\hline Reduce weight / kg & & 790 \\
\hline Weight reduction ratio & & $44.38 \%$ \\
\hline
\end{tabular}




\section{Lightweight optimization design of head cover}

Head cover is fixed on seating ring by bolts of upper ring plate, which is mainly composed of upper ring plate, outer rib plate, middle ring plate, rib plate, middle ring, inner ring, etc. Head cover is equipped with

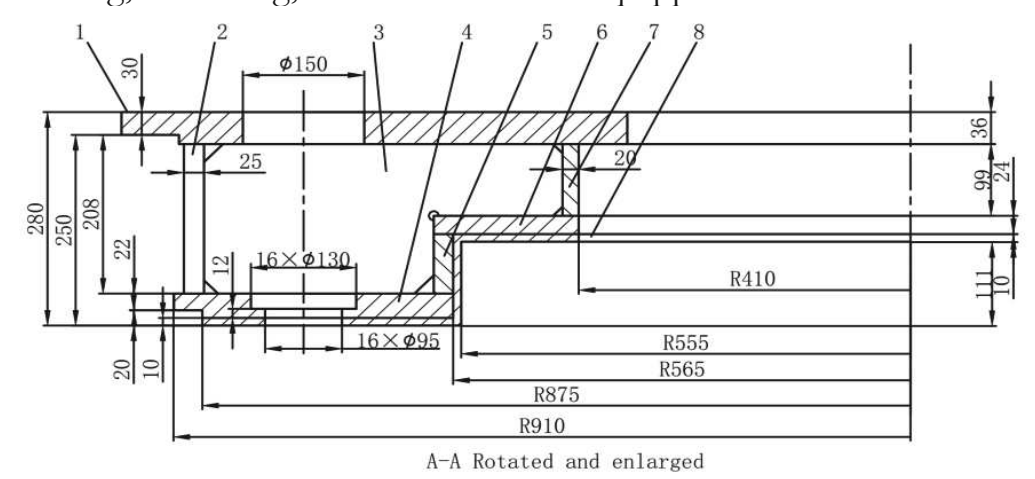

the control ring, drive parts of water guide mechanism and the water guide bearing, etc. Head cover is made of carbon structural steel Q235B with different thickness and stainless steel $06 \mathrm{Cr} 19 \mathrm{Ni10N}$. The structure diagram is shown in Fig. 5.

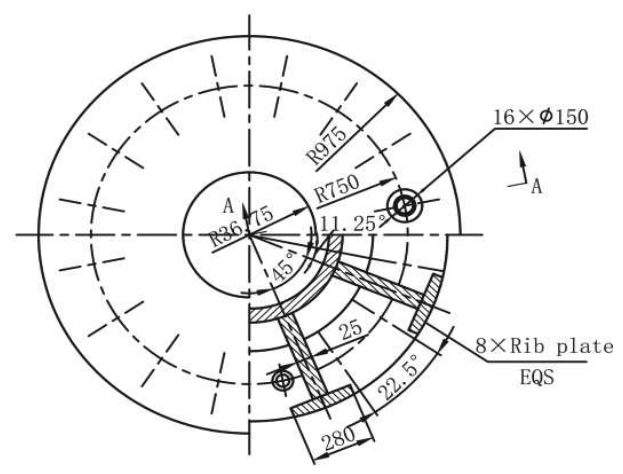

1-Upper ring plate 2-Outer rib plate 3-Rib plate 4-Lowering plate 5-Middle ring 6-Middle ring plate 7-Inner ring 8-Stainless steel liner

Fig. 5 Structure diagram of head cover

A finite element model with 21 element groups, 1088 elements, 544 nodes, and 3264 degrees of freedom is established for head cover by using three-dimensional triangular shell element.

The loads acting on head cover structure are complex and related to the operating state of water turbine. According to design loads of head cover, the loads status under normal operation, emergency stop and seals failure are analyzed, and the largest loads under the most unfavorable working condition are considered [11].

Based on the finite element model, analysis and calculation show that when the head cover subjected to axial load, the maximum displacement occurs in element group 10, at nodes in the middle of two ribs, such as node 488, the maximum displacement

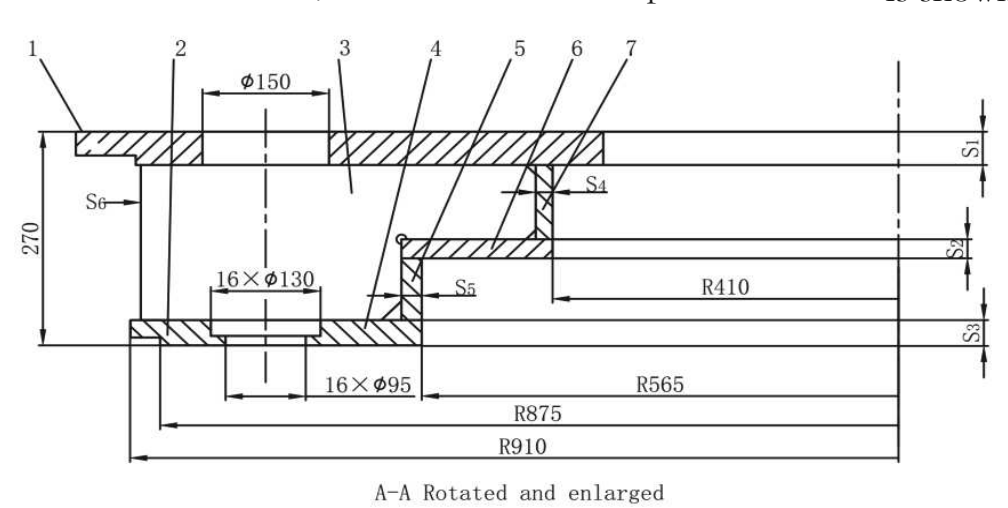
,

$\delta_{\max }=0.421 \mathrm{~mm}$; the maximum normal stress in element group 6 , and the value is $\sigma_{\max }=1.55 \times 10^{8} \mathrm{~N} / \mathrm{m}^{2}$. The maximum deformations of the head cover are located in the upper ring plate and lower ring plate between the rib plates ( 8 rib plates in total), which indicates that the strengthening effects of outer rib plates are not effective. It should consider increasing the quantities or the strength of rib plates to reduce its axial deformation. In view of that should not affect the existing arrangement of other mechanisms and the operation of 16-guide vane mechanism on head cover, the following improvements are proposed: remove the original 8 outer rib plates and retain the 8 existing rib plates, add 8 same rib plates between guide vane holes. The improved head cover structure is shown in Fig. 6.

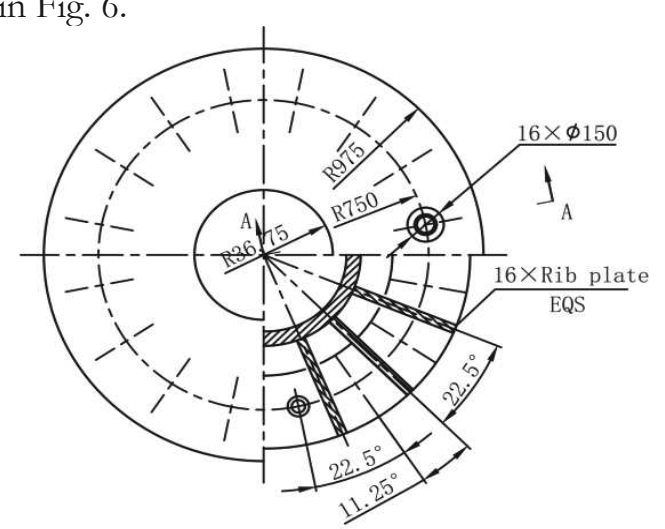

Fig. 6 Structure diagram of improved head cover

For the improved head cover (16 ribs), a finite element model with 28 element groups, 1376 elements and 4032 degrees of freedom is established by using three-dimensional triangular shell element. Six kinds of plate thicknesses $\boldsymbol{X}=\left[x_{1}, x_{2}, \cdots \cdots x_{6}\right]^{\mathrm{T}}$ are selected as design variables, and the head cover mass $W(\boldsymbol{X})$ is taken as the objective function of optimization design. With conforming to stress and deformation as the constraint conditions, the mathematical model of lightweight optimization design is obtained as 


$$
\left\{\begin{array}{c}
\min W(\boldsymbol{X}) \\
\text { s.t. }\left\{\begin{array}{c}
\sigma_{i} \leq\left[\sigma_{i}\right] \quad i=1,2, \cdots, p \\
\delta_{j} \leq\left[\delta_{j}\right] \quad j=1,2, \cdots, h
\end{array}\right. \\
\boldsymbol{X}=\left[x_{1}, x_{2}, \cdots, x_{6}\right]^{\mathrm{T}}
\end{array}\right.
$$

By using the compound form method with optimization iteration, through repeated iteration until the best approximation, the thickness of each plate is determined respectively: $S_{1}=36 \mathrm{~mm}, S_{2}=20 \mathrm{~mm}$, $\mathrm{S}_{3}=32 \mathrm{~mm}, \mathrm{~S}_{4}=20 \mathrm{~mm}, \mathrm{~S}_{5}=20 \mathrm{~mm}, \mathrm{~S}_{6}=15 \mathrm{~mm}$. The maximum stress, maximum displacement and natural frequencies for original and improved finite element model under loads are analyzed and calculated respectively. The comparative results are shown in Tab. 7.

Tab. 7 Comparison of dynamic characteristics of head cover

\begin{tabular}{ccc}
\hline Performance parameter & Original model & Improved Optimized model \\
\hline Maximum displacement $/ \mathrm{mm}$ & 0.421 & 0.253 \\
Node number & 488 & 579 \\
Maximum stress $/ \mathrm{MPa}$ & 155 & 103 \\
Element group number & 6 & 6 \\
\hline First natural frequency $/ \mathrm{Hz}$ & 205.95 & 214.59 \\
Second natural frequency $/ \mathrm{Hz}$ & 288.93 & 308.09 \\
Third natural frequency $/ \mathrm{Hz}$ & 364.43 & 401.08 \\
Fourth natural frequency $/ \mathrm{Hz}$ & 408.43 & 429.82 \\
\hline Structure mass $/ \mathrm{kg}$ & 1900 & 1650 \\
Reduce weight $/ \mathrm{kg}$ & & 250 \\
Weight reduction ratio & & $13.2 \%$ \\
\hline
\end{tabular}

\section{Optimization Effect Evaluation of Hydro Generator Set}

To verify the correctness and effectiveness of the finite element model and lightweight design, the original structures and the optimized structures of upper bracket, stator frame, lower bracket and head cover are tested respectively by hammer impulse exciting. The test data are analyzed by signal processor 7T17S, and the modal parameters are identified. The modal frequencies and modes of the first four modal frequencies were in well agreement with the natural frequencies and modes calculated by the model. The finite element models established well simulate the actual structures, the computed results agree with that of exciting test and modal analysis.

Through lightweight optimization design for the main parts of hydro generator, the maximum stress and maximum displacement of the optimized main parts are within the allowable value range, modal analysis shows that their dynamic characteristics are improved and the performances meet the design requirements. The first natural frequencies of the optimized main parts are still much higher than the runaway frequency $16.04 \mathrm{~Hz}$ of hydro generator and there is no resonance after the lightweight design. The lightweight optimization design reduced the weight of hydro generator by $3457 \mathrm{~kg}$ in total.

The hydro generator set manufactured by the improved design scheme was put into official operation in a hydropower station, after nine months of operation, the original design hydro generator set and the improved design hydro generator set of the same type were site tested at full load $(7000 \mathrm{~kW})$. The main test data are shown in Tab. 8 .

Tab. 8 Comparison of bydro generator set test data of operation status

\begin{tabular}{cccc}
\hline Test parameter and parts & & $\begin{array}{c}\text { Original hydro } \\
\text { generator set }\end{array}$ & $\begin{array}{c}\text { Improved hydro } \\
\text { generator set }\end{array}$ \\
\hline \multirow{2}{*}{ Upper bracket vibration amplitude $/ \mathrm{mm}$} & Axial direction & 0.061 & 0.038 \\
& Radial direction & 0.069 & 0.031 \\
\hline \multirow{2}{*}{ Water guide bearing vibration amplitude $/ \mathrm{mm}$} & Axial direction & 0.13 & 0.068 \\
& Radial direction & 0.17 & 0.076 \\
\hline \multirow{2}{*}{ Noise value in the plant $/ \mathrm{dB}$} & Sound pressure level & 76.79 & 74.7 \\
& sound power level & 93.39 & 91.13 \\
\hline
\end{tabular}

Lightweight optimization design obviously improved the dynamic characteristics and greatly reduced the weight of hydro generator set. The product has reached the national superior product standard and achieved satisfactory economic and social benefits.

\section{Conclusions}

1. According to the actual size and working condition of the upper bracket, stator frame, lower bracket and head cover, finite element models are established and lightweight optimization designs are 
carried out by using sizing optimization design method. The method has practicability and engineering application value.

2. Modal analyses show that the static and dynamic characteristics of the optimized structures are improved. The lightweight optimization design reduced the weight of hydro generator set by $3457 \mathrm{~kg}$ in total.

3. Optimization effect evaluation under full load operation and site test between the original and improved hydro generator set demonstrate that the dynamic characteristics are improved and the performances meet the design requirements.

\section{Acknowledgement}

This work was supported by National Natural Science Foundation of China grants program (61863016) and Yunnan province science and technology plan project (S2016DC069).

\section{References}

[1] YANG H., LIU G., LIU Y., et al. (2014). The current research and development analysis of condition monitoring for hydroelectric generating units. In: Journal of China Institute of Water Resources and Hydropower Research, Vol. 12, No. 3, pp. 300-305.

[2] Sutasn T., Arkarapon S., Wiriyakorn P. (2017). Finite element analysis of counterbore-shaped parts by using sheet-bulk metal forming process. In: Manufacturing Technology, Vol. 17, No. 4, pp. 597-602.

[3] Jan M., Stefan G., Martin P. et al. (2019). Optimization of the runner numerical design dimensions using the simulation program. In: Manufacturing Technology, Vol. 19, No. 2, pp. 273-279.

[4] WANG B., LIU X. L., LIU J. S., et al. (2015). Structural optimization and manufacturing for region of high stress of pelton turbine. In: Journal of Mechanical Engineering, Vol. 51, No. 21, pp.148-155.

[5] LI W., ZHANG H. Q., QIAN Y., et al. (2010). Finite element analysis for outer-movement accidents of stator core laminated sheets of hydro-generator. In: Journal of Zhejiang University (Engineering Science), Vol. 44, No. 5, pp.10321037.

[6] QI X. Y., LI C. C., ZHNG X. J., et al. (2008). The reliability design and calculation of hydraulic turbine head cover. In: Large Electric Macbine and Hydraulic Turbine, No. 2, pp. 40-43.
[7] ZHAO D. L., WANG H. Y., WU Z. J., et al. (2015). Research on rigidity \& strength analysis of Francis runner and improvement measures. In: Journal of Mechanical Strength, Vol. 37, No. 4, pp. $748-753$.

[8] SHAO G. H., WANG Q. Y. (2013). Optimization design of the high specific speed Francis turbine of Zangmu power station. In: Water Sciences and Engineering Technology, No. 3, pp. 51-56.

[9] MARTIN V., LUMÍR H., ADAM B. (2016). Structural damping of mechanical vibration. In: Manufacturing Technology, Vol. 16, No. 6, pp. 1379-1382.

[10] YUAN X. M., MA L., WU P., et al. (2013). Vibration analysis and optimization for upper bracket of high speed suspended hydro generator. In: Macbine Design \& Research, Vol. 29, No. 6, pp. 108-111.

[11] LIAO Y. Y., LIAO B. Y. (2019). Lightweight optimization design of water turbine head cover based on maximum normal stress. In: Journal of Kunming University of Science and Technology (Natural Science), Vol. 44, No. 1, pp. 47-53.

[12] LIAO Y. Y., LIAO B. Y. (2019). Lightweight design of hydro generator upper bracket based on sizing optimization. In: Water Power, Vol. 45, No. 5, pp. 91-94, 117.

[13] LIAO Y. Y., LIAO B. Y. (2019). Finite element analysis and sizing optimization of hydro generator stator frame. In: Chinese Journal of Construction Macbinery, Vol. 17, No. 3, pp. 215-220.

[14] LIAO Y. Y., LIAO B. Y. (2020). Finite element analysis and Lightweight design of hydro generator lower bracket. In: Manufacturing Tecbnology, Vol. 20, No. 1, pp. 66-71.

[15] YAMASAKI S., NISHIWAKI S., YAMADA T., et al. (2010). A structural optimization method based on the level set method using a new geometry-based re-initialization scheme. In: International Journal for Numerical Methods in Engineering, Vol. 83, No. 12, pp. 1580-1624.

[16] CHRISTENSEN P. W., KLARBRING A. (2009). An introduction to structural optimization. Springer, Dordrecht.

[17] MARLER R. T., ARORA J. S. (2004). Survey of multi-objective optimization methods for engineering. In: Structural and Multidisciplinary Optimization, Vol. 26, No. 6, pp. 369-395. 